\title{
EVENTOS SUBCULTURAIS E A CIDADE ESTRATÉGIA PARA A ECONOMIA SIMBÓLICA OU MEIO INTEGRADOR DE UMA CULTURA ALTERNATIVA? O CASO DO FESTIVAL GÓTICO “ENTREMURALHAS” EM LEIRIA
}

\section{SUBCULTURAL EVENTS AND THE CITY: STRATEGY FOR THE SYMBOLIC ECONOMY OR AN INTEGRATOR OF AN ALTERNATIVE CULTURE? THE CASE OF THE GOTHIC “ENTREMURALHAS" FESTIVAL IN LEIRIA}

\author{
Manuel Pereira Soares \\ Universidade de Coimbra, Faculdade de Economia, Departamento de Sociologia. Avenida Dr. Dias da Silva, \\ 3004-512 Coimbra, Portugal. \\ E-mail: manuelpsoares@gmail.com | ORCID: http://orcid.org/0000-0003-3057-3283
}

Resumo: A cidade é um espaço de diversidade onde se verificam conflitos e tensões entre culturas dominantes e alternativas. Os festivais, funcionando como alavanca para o desenvolvimento das cidades, colocam também em contacto diferentes culturas e podem contribuir para desfazer estereótipos e atenuar estigmatizações.

Este artigo pretende descortinar como é que um evento subcultural pode promover a imagem de uma cidade enquanto espaço de cultura e diversidade. Recorre-se ao festival gótico Entremuralhas e cruza-se a análise de material produzido pelo município com notícias sobre o evento publicadas em jornais, procurando perceber como o festival é comunicado à população e como os membros da comunidade gótica o percecionam no que concerne ao dissipar dos estereótipos. Conclui-se que o festival tem sido apresentado como um dos mais importantes elementos de promoção da cidade ao mesmo tempo que observamos que persistem alguns dos estereótipos em relação a esta subcultura.

Palavras-chave: festival Entremuralhas, subcultura gótica, estereótipos, festivalização da cidade.

Abstract: The city is a space of diversity with conflicts and tensions between dominant and alternative cultures. Festivals, acting as a leverage for the development of cities, bring different cultures into contact and can contribute to break down stereotypes and reduce stigma.

This article assesses how a subcultural event can promote the image of a city as a space of culture and diversity. We analyzed promotional material produced by the municipality and articles about the Entremuralhas gothic festival published in newspapers. This allowed an understanding how the festival is communicated to the population and how members of the gothic community perceive it in terms of dispelling of stereotypes. It is concluded that the festival has been presented as one of the most important elements of city promotion, but that some of the stereotypes persist.

Keywords: Entremuralhas festival, gothic subculture, stereotypes, city festivalization. 


\section{Introdução}

Vivemos num mundo que se urbaniza a cada dia que passa. As cidades carregam consigo a sua apetência pela heterogeneidade, dimensão e densidade (Wirth, 2001). Contudo, a coexistência de culturas diferentes num mesmo espaço potencia o surgimento de tensões e conflitos, algo que desde a Escola de Chicago vem despertando o interesse dos sociólogos.

Num mundo globalizado a cultura representa as ideias e práticas, os locais e símbolos do que tem sido chamado de "economia simbólica" das cidades (Zukin, 2014, p. 3), transformando-as em mercadorias e bens como outros quaisquer, o que as torna competitivas na disputa pelo seu espaço no mercado global. Nesta linha de argumentação, as cidades procuram convocar os seus recursos endógenos no sentido de se promoverem, utilizando a cultura como forma de criar imagens de marca distintivas (Richards \& Palmer, 2010, p. 2). Não se pode atualmente falar de cidades "sem entender como (elas) utilizam a cultura como base económica" (Zukin, 1995 , p. 11). Os eventos culturais, especialmente os festivais, assumem, neste particular, um papel preponderante para a criação de uma marca distintiva, constituindo-se como uma ferramenta à qual autarcas e agentes do marketing de lugar recorrem frequentemente como uma forma rápida, acessível e temporária de promoção de uma cidade (Wynn \& Yetis-Bayraktar, 2016, p. 204) Argumenta-se, cada vez mais, que as cidades que assumem os eventos culturais como parte de uma estratégia para o seu desenvolvimento têm mais probabilidades de colher benefícios sociais, económicos e culturais (Richards \& Palmer, 2010, p. 2).

Nas cidades, podem encontrar-se duas situações distintas: $i)$ a presença de subculturas e diversidade cultural, por um lado; ii) o uso da diversidade subcultural como estratégia nas políticas urbanas, por outro. A literatura produzida sobre a diferença na cidade centra, por norma, a discussão no tema das diferenças étnicas, raciais ou religiosas, incidindo a sua análise na questão do multiculturalismo e nos desafios com que os planeadores das cidades têm de conviver para lidarem com esse tema numa era de migrações (Sandercock, 2003, p. 4). Mas existem outras formas de diferença nas cidades, como a que contempla a coexistência de diversas expressões culturais e estilos de vida no espaço urbano, principalmente numa altura em que essa diversidade se transforma, cada vez mais, em estratégia das políticas urbanas para a criação de espaços cosmopolitas e abertos que visam construir novas imagens mercadorizáveis, olvidando, muitas vezes, que os atores dessa diversidade devem ser vistos e tratados como sujeitos e não apenas como "décor" dessa evolução urbana (Fortuna, 2016). 
Já existe em Portugal pesquisa sólida relativamente a culturas musicais alternativas (Guerra, 2010; Guerra \& Moura, 2016), mas verifica-se ainda escassez de produção científica sobre a forma como a coabitação entre culturas alternativas e dominantes nas cidades se combina com processos de festivalização, culturalização e gentrificação dos espaços urbanos (Bennett, Taylor \& Woodward, 2014; Evans, 2011; Ferreira, 2010). As cidades tentam aproveitar as suas especificidades e recursos para se regenerarem e crescerem cultural e economicamente (Richards \& Palmer, 2010), e a aposta na cultura afigura-se como central para elas procurarem encontrar o seu espaço na competição entre cidades, constituindo-se essa estratégia como uma forma de notabilização e promoção de imagens que se constroem e divulgam, falando-se, cada vez mais, em cidades de eventos (Evans, 2011; Richards \& Palmer, 2010). A simples existência de uma cena musical consolidada numa cidade pode trazer-lhe, e à comunidade, benefícios através do turismo, como nos recorda Andy Bennett (2004, p. 228). A cidade funciona como meio onde as dinâmicas culturais se geram e também através do qual se realizam, fornecendo o conjunto infraestrutural que permite a sua emergência (Guerra \& Moura, 2016, p. 4). Esses eventos são muitas vezes utilizados para construir imagens de espaços tolerantes, abertos à diversidade e cosmopolitas (Chalcraft, Delanty \& Sassatelli, 2014), especialmente nas cidades de pequena e média dimensão que "procuram e disputam a afirmação no plano regional e nacional" e onde "a cultura assume um valor estratégico importante" (Abreu, 2001, p. 161).

Ressalta, portanto, a ideia que os festivais podem funcionar como agentes e como produtores de cosmopolitismo (Chalcraft, Delanty \& Sassatelli, 2014, p. 111), afigurando-se como uma das mais importantes formas de conexão de pessoas, culturas e ideias, podendo atuar como atores socias, e funcionando como algo mais que objetos, isto é, também como sujeitos (Richards, 2015, p.1) ao mesmo tempo que enriquecem a cultura cosmopolita das cidades, encorajando os residentes urbanos a tornarem-se consumidores culturais polimórficos, tornando-os mais tolerantes com os estranhos na sua comunidade e mais ligados ao que vem de fora (Zukin, 2014). Interessa perceber em que medida os festivais podem atuar enquanto meio atenuador de tensões existentes entre culturas dominantes e alternativas em espaço urbano, procurando descortinar que contributo esses eventos dão, de facto, para a conquista de espaço por parte destas culturas alternativas, e perceber se eles podem funcionar como elementos agregadores entre os diversos grupos ao mesmo tempo que potenciam o desenvolvimento económico dos lugares, especialmente numa altura em que se procura, cada vez mais, perceber o papel que a música pode assumir na tarefa de tornar as cidades mais ricas, saudáveis, habitáveis e internacionais (Baker, 2019, p. 12). 
A diversidade cultural, e em particular as culturas alternativas, constituem fenómenos desafiantes para a compreensão dos processos culturais que transformam as cidades, remetendo para problemáticas sociológicas como as relações de convivência e tensão entre culturas e modos de vida distintos. Os festivais, ao permitirem àqueles que pertencem à cultura dominante imergir durante algum tempo na cultura do outro (Bennett \& Woodward, 2014, p. 12), possibilitam que eles possam adquirir um melhor conhecimento da cultura alternativa, desfazendo, desse modo, estereótipos e servindo de alavanca para o desenvolvimento e promoção dos territórios.

\section{Duplo papel da cultura: criadora de imagens da cidade e facilitadora de integração}

A cidade é composta de gente heterogénea e depreende uma certa normalização da ideia do anonimato, sendo vista como um espaço inato para estranhos e lugar propício para "desenvolver uma cultura de diferença" (Innerarity, 2006). A distinção que desponta entre a cidade e a pequena localidade é o facto de na cidade causar admiração encontrar alguém conhecido, enquanto na aldeia sobressai o estranho, o que não pertence àquele espaço (Innerarity, 2006).

O urbanismo em si afigura-se como uma variável que tem efeitos sociais, já o defendia Claude Fischer (1975, p. 1320). O mesmo autor afirmava que os valores mais elevados de "desvio" e desorganização nas cidades não se deviam tanto a fatores como a alienação, anonimato e impersonalidade, mas sim à congregação de elevado número de pessoas, de massa crítica em número suficiente para manterem viáveis subculturas (Fischer, 1975, p. 1320).

Pelas suas especificidades, e também muito devido à sua diversidade, as cidades constituem-se, portanto, como espaços privilegiados da arte e da cultura, e são-no a vários níveis, desde a produção e consumo cultural, até ao facto de serem “objetos de representação estética e de valor artístico, cuja singularidade reside tanto na sua configuração arquitectónica como nas formas da vida social e cultural que pulsam no seu interior" (Abreu \& Ferreira, 2016, p. 3). Pelo papel preponderante que a cultura assume para as cidades, as políticas urbanas têm-lhe dedicado cada vez mais atenção no planeamento e no gizar de políticas de desenvolvimento urbano (Abreu \& Ferreira, 2016, p. 3). A cultura na cidade, significa (ou pode significar) desenvolvimento económico, atratividade, mercadorização das imagens da urbe que vão sendo construídas, muito da linha do que Lefebvre chama de "urbanismo dos promotores", em que o urbanismo visa o lucro e se transforma em valor de troca (Lefebvre, 2012, p. 37), interessando apresentar a cidade, e os seus lugares, 
como imaginários de bem viver. É ela que "lança as modas e as legitima, mas é também nela que "fervilham os conflitos e as tensões, pelo que é comum falar-se em mosaico cultural quando pretendemos referir-nos à cidade" (Lopes, 2000, pp. 67-68). Interessa, então, que os eventos tenham efetivamente impactos visíveis, pelo que os apoios à cultura estão cada vez mais indexados a um conjunto de indicadores de performance, uma vez que, embora efémeros, os eventos geram capital simbólico, a mais valiosa mercadoria da atualidade (Richards \& Palmer, 2010, pp. 11-12).

Muitos dos festivais destinam-se a nichos e funcionam como eventos ligados a estilos de vida (Bennett \& Woodward, 2014, pp. 12-13). Neste sentido, eles podem ser tanto agentes como produtores de cosmopolitismo (Chalcraft, Delanty \& Sassatelli, 2014, p. 111). Permitem, então, que esse cosmopolitismo se manifeste das mais diversas formas: através do lugar do evento, do contexto cultural ou através das pessoas (Chalcraft, Delanty \& Sassatelli, 2014, p.111). Cumprem, assim, a função de meio para representar, encontrar, incorporar e perceber as diferenças culturais a partir do momento em que colocam em contacto pessoas com diferentes experiências e interesses (Bennett \& Woodward, 2014, p. 18).

A cultura vai, portanto, assumindo um papel mais instrumental no significado das cidades, principalmente numa altura em que a globalização e o acesso a mais informação e imagens enriquece a sua cultura cosmopolita. Talvez seja por isso que se observe cada vez mais pressão para que as instituições culturais diversifiquem a oferta para poder abranger públicos mais vastos (Zukin, 1995, p. 2).

Em Portugal, eventos como o Festival Músicas do Mundo, em Sines, o Festival Islâmico, em Mértola, o Boom Festival, em Idanha-a-Nova e o festival gótico Entremuralhas, em Leiria, são ilustrativos de eventos que colocam o seu foco nas culturas alternativas e na diversidade cultural. Por norma, o estudo em Portugal do impacto dos festivais de cariz cultural e subcultural tem incidido sobre a questão económica (Antunes, 2020), fazendo-se já algum trabalho também em relação à forma como eles são acolhidos por parte dos residentes locais (Brás, Mendes, Guerreiro \& Sequeira, 2019).

A subcultura gótica conta com a realização de vários festivais um pouco por todo o mundo. A importância que é concedida à questão da promoção do lugar, por um lado, e à da interação entre cultura dominante e alternativa, por outro, varia conforme o evento. Aproveitando a ligação que tem com o livro Dracula de Bram Stoker, que foi parcialmente escrito em Whitby (Spracklen \& Spracklen, 2014), ainda antes do surgimento do festival gótico a cidade acolhia já muitos aficionados da obra deste autor e do universo vampírico, recriando cenários presentes no livro e permitindo aos seus visitantes experimentarem uma vivência próxima do ambiente do romance, 
tendo a cidade assistido à abertura de várias lojas especializadas em vestuário e acessórios ligados ao universo do livro (Spracklen \& Spracklen, 2018), o que permitia aos seus visitantes reviverem episódios do romance. O festival gótico de Whitby, realizado anualmente em dois momentos, um em abril e outro em outubro no fim de semana do Halloween, trouxe um contributo para que a cidade se tornasse uma atração turística que acolhe milhares de visitantes, especialmente nos dois fins de semana correspondentes ao evento. A grande teatralidade que os frequentadores emprestam ao festival, desfilando por aqueles dias hordas de góticos pelas ruas da cidade, coloca ênfase na ideia que aquele "teatro" atua como reflexo da vida, e o festival funciona como um pedaço dessa vida real (Goulding \& Saren, 2016, p. 218). Contudo, toda esta espetacularidade tem funcionado como fator de atração para muitos curiosos e fotógrafos amadores que se deslocam ao evento para verem os góticos e tirarem o máximo de fotografias que alimentarão as redes sociais (Spracklen \& Spracklen, 2018). Este facto tem motivado algumas tensões com a comunidade local e com a própria comunidade gótica, especialmente pelo facto de muitos dos visitantes procurarem apenas viver uma experiência diferente, sem serem verdadeiramente integrantes desta subcultura, e utilizarem espaços como o cemitério para sessões fotográficas, o que tem desagradado tanto aos residentes locais, que sentem desrespeitados os seus familiares ali sepultados, como aos góticos que veem a sua cultura ser mercadorizada e tornada um produto de massas, perdendo a sua autenticidade (Spracklen \& Spracklen, 2014). O evento tem-se tornado uma forma de promoção da cidade e a constante mercantilização da subcultura tem afastado cada vez mais góticos "verdadeiros" do festival, obrigando os organizadores a abrir o cartaz a bandas não diretamente relacionadas com a cultura gótica, com vista a procurar atrair mais espetadores (Spracklen \& Spracklen, 2018).

O Wave Gotik Treffen (WGT) é provavelmente o maior festival gótico do mundo. Localizado na cidade de Leipzig, cidade da antiga RDA, conheceu a sua primeira edição em 1992, já depois da queda do Muro de Berlim, acolhendo cerca de 2000 góticos que assistiram aos concertos num único local (Hoffert \& Nym, 2011, p. 4). Atualmente, o evento recebe mais de 20000 espetadores e vê os seus espetáculos espalhados por toda a cidade. Para a comunidade gótica este evento é um acontecimento importante, como atesta uma trilogia escrita sobre a subcultura gótica e que dedica grande parte da atenção do primeiro volume ao festival WGT (Matzke, Seeliger \& Stieg, 2000). Para a cidade, o festival também se constitui um dos seus principais eventos culturais realizados anualmente, trabalhando o município de forma estreita com a organização do evento, como atesta o convite feito aos ingleses In the Nursery para, em 2007, integrado na edição do festival WGT desse ano, criarem o espetáculo de luz e música intitulado Monumentum II, que serviu 
para homenagear compositores como Bach, Wagner, Liszt e Mendelssohn, todos eles com ligações à cidade, tendo por cenário o principal monumento de Leipzig, o Völkerschlachtdenkmal (Humberstone, 2011).

\section{Cidade como espaço para subculturas}

Claude Fischer, no seu texto sobre a teoria subcultural do urbanismo, afirmava que a concentração de populações heterogéneas em grande número num mesmo espaço conduzia ao enfraquecimento dos laços interpessoais, das estruturas sociais primárias e do consenso normativo, tendo como consequências dessa realidade a alienação individual, anomia societal e a prevalência de comportamentos desorganizados, não tradicionais e desviantes (Fischer, 1975, p. 1320). O desafio que aqui se coloca é perceber se quando se assume uma determinada ordem cultural como dominante isso implica a subordinação ativa das alternativas (Hall, 2001, p. 89).

O tema das subculturas tem sido estudado desde inícios do séc. XX assentando, essencialmente, em duas vertentes: a do desvio, desenvolvida pela Escola de Chicago, (Becker, 1973; Berzano \& Genova, 2015; Gelder, 2007; Gelder \& Thornton, 1997; Haenfler, 2014; Williams, 2014) e a da resistência de classe, resultado dos trabalhos do Centro de Estudos Culturais Contemporâneos da Universidade de Birmingham (CCCS) (Brake, 1995; Gelder, 2007; Gelder \& Thornton, 1997; Haenfler, 2014; Hall \& Jefferson, 2003; Hebdige, 2005; Muggleton, 2000). São duas abordagens diferentes ao tema, mas mantém-se, em ambos os casos, a ideia que ao falar-se de subculturas está-se a referir a algo que sai da normatividade, que se apresenta como uma alternativa ao que é dominante, independentemente de se justificar esse facto com questões de comportamento, de resistência ou outras ainda. Fischer procurou relacionar o surgimento e desenvolvimento das subculturas com a densidade e dimensão das cidades. Nessa perspetiva, quanto mais urbano um lugar maior a diversidade e intensidade das subculturas existentes, da mesma forma que quanto mais urbano um lugar, maiores as formas de difusão das subculturas e maiores os graus de "inconvencionalidade" do lugar, procurando, portanto, conferir às subculturas um caráter eminentemente urbano (Fischer, 1975).

Os estudos pós-subculturalistas têm identificado novas formas de agrupamento subcultural, como as neo-tribos, estilos de vida e cenas (Muggleton \& Weinzierl, 2003; Redhead, 1997; Thornton, 1995). Importa destacar que, mantendo os habituais temas da identidade, e das relações centro-periferia (assentes nas lutas e tensões entre a cultura dominante e a não normativa ou marginalizada), os trabalhos mais recentes sobre as subculturas trazem novos temas para a discussão, como o dos meios de comunicação social e as novas tecnologias de informação, que têm 
oferecido novas formas de visualizar as comunidades e permitem novas possibilidades de construção de identidades (Williams, 2019, pp. 5-7). Para Emre Ulusoy (2016, p. 244) as subculturas musicais dionisíacas proporcionam os meios para os seus consumidores encontrarem um conjunto de possibilidades para se autoexpressarem de formas alternativas, fornecendo estas subculturas espaços sociais onde podem ser experimentadas e recriadas identidades, enquanto se recusa o papel de mero espetador (Ulusoy, 2016, p. 247).

Mais do que procurar perceber se determinado grupo se enquadra em subcultura ou tribo, estilo de vida, cena ou uma mescla de todas elas, interessa aqui referir a visibilidade que estes grupos assumem no espaço urbano, e as tensões que muitas vezes daí decorrem, sendo a atividade desviante determinada pela cultura dominante, sem que aqueles que pertencem a esses grupos tenham de, necessariamente, aceitar a ideia de que praticam atos desviantes (Becker, 1997, p. 56). E, nesse particular, é interessante atentar na variedade de subculturas que vão conquistando notoriedade em contexto urbano ao ponto de a sua ocupação do espaço determinar alterações às funções que os planeadores lhes destinaram inicialmente, passando esses grupos (como no caso dos skaters, por exemplo) a ser conhecidos como formações sociais urbanas em vez de subculturas (Daskalaki \& Mould, 2013). Interessa ressalvar como a subculturalização vive dois momentos: o do surgimento, em que são o "outro" através da sua marginalização e ilegalização, e um segundo, em que as forças homogeneizantes as formalizam e incorporam nas práticas dominantes e as transformam em produtos subjugados aos processos de comercialização (Daskalaki \& Mould, 2013, p. 2). Sabendo que a cidade se ancora na cultura para fins de desenvolvimento, este aspeto é importante para perceber a função que os festivais têm (ou podem ter) para a aceitação das culturas alternativas, não apenas por permitir colocá-las em contacto com a cultura dominante, mas também pelos proveitos comerciais e de notoriedade que esta última daí pode retirar.

\section{Apresentação do caso do Festival Entremuralhas}

A literatura que tem sido produzida sobre a subcultura gótica aponta para Inglaterra e para o final dos anos 70 do século passado como sendo o local e o momento em que esta subcultura surgiu (Brill, 2008; Goodland \& Bibby, 2007; Hodkinson, 2002; Issit, 2011; Newman, 2018; Siegel, 2005). Ela caracteriza-se por se associar a diversas formas de expressão artística, indo buscar inspiração à literatura gótica, ao culto dos vampiros, aos filmes de horror e às praticas sexuais menos convencionais (Goodland \& Bibby, 2007, p. 2), ou seja, tudo aquilo que, de alguma forma, a cultura dominante considera como saindo da normatividade. 
O visual dos góticos, assente nas vestes negras produzidas pelos próprios (Hodkinson, 2002, pp. 151-181), não propriamente encontradas nas lojas convencionais e muitas vezes fruto da bricolage típica das subculturas (Hebdige, 2005), e as pinturas faciais claramente fora da norma contribuem para que a comunidade gótica se destaque facilmente nos meios urbanos onde marca presença. Neste sentido, os festivais e eventos dedicados à cultura gótica funcionam como uma forma de os seus integrantes poderem adquirir alguns objetos, como roupas e acessórios, tarefa que, de outra forma, veem dificultada quando ficam limitados ao comércio convencional, salvo algumas peças que a cultura dominante acaba por adotar e mercantilizar, incorporando-as no comércio de massas (Hodkinson, 2002, pp. 131-151).

A subcultura gótica pouca atenção tem mobilizado, quer por parte dos media quer dos académicos (Martin, 2002), e quando tal acontece é por motivos menos abonatórios (Brill, 2008; Garland \& Hodkinson, 2014; Goodland \& Bibby, 2007; Issit, 2011; Newman, 2018; Siegel, 2005). A ideia estereotipada em relação a esta subcultura, talvez influenciada pelo visual ao qual não se fica indiferente e que cria discriminações, inclusivamente no local de trabalho (Fauquet-Alekhine, 2015), e o interesse por temas como a morte faz com que muitos estereótipos sejam criados e difundidos relativamente aos seus integrantes. Contribui também para a construção desses estereótipos em relação a esta subcultura a apropriação de objetos culturais, como crucifixos e outros símbolos religiosos, por exemplo, aos quais os góticos conferem novos significados, utilizando-os para, visualmente, construírem novas mensagens contraculturais (Healey \& Fraser, 2017, p. 12), o que potencialmente pode ser um fator gerador de tensões entre culturas diferentes.

Em Portugal, em final dos anos 1990 e início de 2000, assistiu-se a algum dinamismo desta cultura alternativa, especialmente em Lisboa e no Porto. O Norte, aliás, contou com uma comunidade muito ativa, tendo a discoteca Heavens sido uma referência para os góticos do norte do país, a par com a loja de discos Division House, em Oliveira de Azeméis, responsável pela organização de muitos dos concertos em Portugal de bandas de referência desta subcultura. Lisboa concentra parte significativa dos góticos portugueses, albergando também o grupo Phantom Vision, aquela que, provavelmente, é a mais conhecida banda nacional do género ainda no ativo. Também na capital encontra-se a Equilibriummusic que também tem tido um papel importante no panorama nacional enquanto distribuidora da música de muitas das bandas desta cultura alternativa, e também através do seu papel enquanto editora de alguns projetos nacionais e internacionais. Outra forma de divulgação da subcultura deu-se até inícios de 2000 através da organização de Dark Nights em bares e discotecas em várias cidades do país. Estes eventos eram organizados, por norma, por membros desta subcultura provenientes de Lisboa ou do 
Porto e constituíam-se como uma possibilidade de levar a cultura gótica até cidades mais pequenas onde havia menos membros.

Mas é em Leiria que, fora dos dois grandes centros nacionais, esta subcultura tem conhecido considerável atividade. O festival Entremuralhas é organizado pela Associação Cultural Fade In, que desde há 20 anos organiza em Leiria concertos e espetáculos com bandas ligadas a esta cultura alternativa, dinamizando um dos seus responsáveis, desde há muitos anos, um programa de rádio, que atualmente ocorre online, que dá a conhecer música e bandas da subcultura em questão. O festival conheceu a sua primeira edição em agosto de 2010 e tem-se realizado anualmente. Ao longo dos últimos dez anos, o evento registou crescimento e notoriedade assinaláveis e saltou as muralhas do castelo de Leiria (onde começou por se realizar) para a cidade, tornando-se, entretanto, um dos eventos internacionais de referência da cultura gótica.

\section{Metodologia}

Este trabalho teve por base a análise de documentos relativamente ao festival Entremuralhas produzidos pela Câmara Municipal de Leiria (CML) e por organismos oficiais de promoção e divulgação do turismo do Centro e que se encontram disponibilizados online ou publicados em formato impresso. Além destes documentos, fez-se também uma pesquisa ao conjunto de notícias relativas ao festival Entremuralhas publicadas entre 2010 (primeira edição) e 2019 (última edição) nos sites de jornais locais e nacionais e também em sites de música. Dedicou-se especial atenção aos artigos/notícias com entrevistas/declarações dos organizadores e participantes do evento relativamente à experiência vivida e intenções do festival, tendo-se, igualmente, feito uma análise às caixas de comentários dos diversos meios de comunicação online pesquisados. Para confrontar as informações obtidas através da análise destes documentos com as perceções da comunidade gótica em relação à importância e ao impacto do festival para a sua vivência subcultural, solicitou-se que alguns membros desta comunidade respondessem a um pequeno inquérito construído na plataforma eletrónica Google Forms.

\section{Resultados}

Notícias e referências ao festival Entremuralhas

Procedeu-se ao levantamento de todas as notícias e referências ao festival verificadas no período compreendido entre 2010 e 2019. Para tal, efetuou-se a procura no motor de busca eletrónico Google recorrendo à expressão Festival Entremuralhas. 


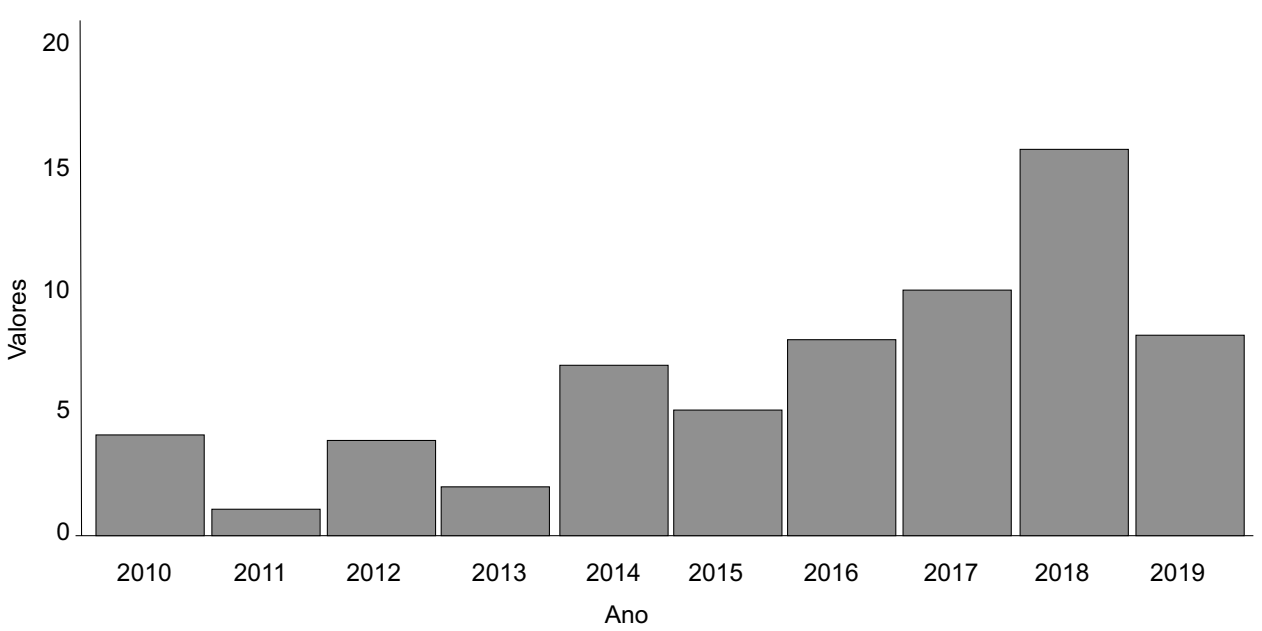

Figura 1 Notícias e referências online ao festival Entremuralhas entre 2010-2019

Identificaram-se 65 notícias e referências, observando-se um aumento consistente do número de ocorrências ao longo das dez edições do evento, com especial destaque para o ano 2018, altura em que o festival saiu do castelo e passou a realizar-se um pouco por toda a cidade (Figura 1).

\section{Análise}

Da análise dos documentos que a Câmara de Leiria produziu, constata-se que o festival tem sido considerado como um dos eventos mais importantes para a promoção da cidade. Isso fica patente quando se lê que:

(...) O “Festival Gótico Entremuralhas" é um evento turístico com repercussões a nível mundial que tem obtido um enorme sucesso de caráter sociocultural e económico, essencialmente, na cidade de Leiria.

Esta reedição é a demonstração de que o nome da cidade de Leiria tem viajado por inúmeros países, sendo estes três dias um importante marco não só para a notoriedade positiva de Leiria como também um estímulo para a economia local, nomeadamente a hotelaria e restauração (Valentim, Manuel, Marques, Madureira \& Marques, 2017, p. 36)

Percebe-se, através deste excerto, que o poder local entende o festival como sendo positivo para a notoriedade e imagem da cidade, gerando também "benefícios 
económicos e culturais para o concelho" como afirma o vereador Gonçalo Lopes, responsável pela cultura em Leiria em 2014 e atual presidente do município (Diário de Leiria, 2014). O anterior presidente da Câmara Municipal, Raul Castro, referia-se em 2017 ao festival Entremuralhas como um dos eventos que trazia mais gente de fora do país a Leiria, afirmando que o evento "conquistou o estatuto de cabeça de cartaz da programação cultural da cidade" (Expresso, 2017), algo nada despiciendo se tivermos em conta a candidatura que o respetivo município desenvolve atualmente para ser Capital Europeia da Cultura em 2027.

O festival funciona, portanto, como forma de colocar em contacto culturas distintas. Os restantes membros da comunidade de Leiria, ao terem a oportunidade de imergir na cultura alternativa por alguns dias, podem obter um melhor conhecimento de algo que lhes parece estranho e impregnado de estereótipos. Nesse sentido, atente-se à afirmação que o festival "seduz os habitantes de Leiria a vestirem as suas roupas e rendas negras" (Jornal de Leiria, 2016), residentes que são apresentados como sendo "pessoas simpáticas, dispostas a ajudar e até já se habituaram às centenas de góticos que por lá passam em Agosto" (Ultraje.pt, 2016).

Importa destacar que Leiria é atualmente "considerada pelos forasteiros uma cidade socialmente e culturalmente vanguardista e emancipada", destacando-se a importância do impacto do festival em "tornar Leiria numa boa notícia nacional e internacionalmente e, sobretudo, pela responsabilidade que tem tido na transformação do olhar que cada um de nós tem tido perante o que é culturalmente/ socialmente diferente e não mainstream", afigurando-se como um caminho para a abertura de mentes (Jornal de Leiria, 2016).

O festival, mais do que ser apenas um momento ritual de encontro da comunidade gótica, tem também sido utilizado como meio de aproximação entre culturas. O facto de ele se realizar, durante várias edições, no interior do castelo acabava por não permitir que a restante comunidade pudesse contactar de perto com o evento, pelo que surgiu, em 2014, a vontade de levar alguns espetáculos para fora do recinto do festival, abrindo a programação à restante comunidade através de um concerto gratuito para permitir "desfazer os preconceitos que subsistem em torno do rótulo de festival gótico" (Região de Leiria, 2013). A ideia de recorrer ao evento para colocar em contacto culturas que convivem em tensão parece ser uma constante, como atesta o lema da edição 2014: "Entremuralhas - Porque uma experiência vivida é bem diferente de uma contada" (Região de Leiria, 2013). A caixa de comentários do site desta notícia é bem ilustrativa da oportunidade que os eventos culturais constituem ao colocar em contacto diferentes culturas: "Eu por exemplo tenho imensa curiosidade em ver como é o ambiente e assim, mas como não faço parte da "cultura gótica não me compensa comprar um bilhete" ou ainda "Eu 
também tenho curiosidade em ver o ambiente dum festival como este, muitos metaleiros são descriminados, por se inserir numa cultura como esta e assim, podia se quebrar, a tal barreira psicológica" [transcrição literal dos comentários] (Região de Leiria, 2013).

As notícias que se vão publicando sobre o evento demonstram que a comunidade leiriense vai-se envolvendo com o festival, pelo menos em termos económicos, como fica claro quando se lê numa das notícias que, finalmente, ao fim de sete edições, existe uma procura pró-ativa por parte de alguns parceiros do festival, nomeadamente da hotelaria e da restauração, em associarem-se de forma mais incisiva ao festival (Jornal de Leiria, 2016).

Mas nem todas as tensões conseguem ser ultrapassadas. Em 2018, devido a obras de requalificação no Castelo de Leiria, o festival realizou-se fora daquele espaço em vários equipamentos e lugares da cidade. Se, por um lado, isto permitiu colocar os residentes de Leiria em contacto direto com o festival, também deixou transparecer alguns dos estereótipos que persistem em relação à subcultura. Um dos momentos dessa tensão prendeu-se com a mudança de dois concertos inicialmente agendados para uma antiga igreja dessacralizada convertida em espaço cultural. A razão dessa mudança surgiu na sequência da polémica ocorrida uns meses antes com a realização de um espetáculo do festival Metadança, também em Leiria, e que, no entender de alguns vereadores da oposição e de entidades religiosas da cidade, foi atentatório do espaço em causa (dessacralizado), pois os bailarinos apresentaram-se em trajes considerados não adequados ao espaço em questão (Diário de Notícias, 2018a; Sapo.pt, 2018). O executivo camarário, coorganizador do Entremuralhas, determinou a mudança daqueles dois espetáculos para outro lugar, mantendo o seu papel de parceiro do festival. Registe-se a declaração de Carlos Matos, da direção da Fade In, coorganizadora do evento, afirmando que por ele nunca mudaria os concertos de lugar, pois eles nada tinham de ofensivo e que a censura artística era absurda, lembrando os 25 anos que vem levando de luta pela mudança de mentalidades na cidade, mas que parece não conseguir efeitos perante o "clero radical" (Sapo.pt, 2018). Este é um exemplo de como nestas lutas de poder a cultura dominante consegue exercer a sua influência e impor-se à cultura que lhe está à margem.

Na caixa de comentários de uma das reportagens da edição 2018 um leitor repudia o que considera "a incompetência e o sentido de dar nas vistas sem fazer nada" dos festivaleiros, defendendo que quem é competente na vida e no trabalho "não precisa de se tatuar nem colocar piercings para dar nas vistas". O comentário obteve réplica de outro leitor que recordou o caráter competente da equipa de amadores que organiza o festival e salientando que também o público do festival tem 
"de ser competente nas suas profissões para suportar as viagens, estadias, refeições e afins" e dinamizarem "a economia de uma região" que, afinal, não é "só Fátima" (TSF, 2018). Ainda na mesma caixa de comentários, outro leitor, em resposta a outra observação que rotula os organizadores e participantes do Entremuralhas de "mentes reprimidas" alude ao episódio da mudança dos dois concertos da edição desse ano, denunciando que essas mentes podem ser encontradas na igreja "que no séc. XXI ainda se acha no papel de censor e no direito de castrar a cultura segundo os seus padrões e interesses ou das pessoas que julgam o caráter, os princípios ou o profissionalismo de outras pelo aspeto".

Numa leitura daquela que se entendeu ser uma das mais completas notícias sobre o festival (Diário de Notícias, 2018b) é possível identificar algumas expressões que se enquadram em três diferentes categorias de análise identificadas: i) promoção da cidade; ii) preconceitos em relação à comunidade gótica; iii) argumentos contra os preconceitos. Na Tabela 1 apresentam-se os excertos mais significativos identificados em relação a cada uma destas categorias, destacando-se a negrito as palavras e expressões consideradas mais pertinentes para esta análise.

Tabela 1 Análise de notícia com base em três categorias

\begin{tabular}{|c|c|c|}
\hline \multicolumn{3}{|c|}{ Categorias } \\
\hline Promoção da cidade & $\begin{array}{l}\text { Preconceitos em relação aos } \\
\text { góticos }\end{array}$ & Argumentos contra os preconceitos \\
\hline $\begin{array}{l}\text { "...encontram-se por ali os amantes } \\
\text { de um certo estilo musical, pois que } \\
\text { sabem ser o único festival em } \\
\text { Portugal onde é possível ver e ouvir } \\
\text { "aquela" música" }\end{array}$ & $\begin{array}{l}\text { “...no dia em que a organização faz } \\
\text { o seu primeiro teste fora das } \\
\text { muralhas, onde o público - gótico, } \\
\text { na sua maioria - estava "mais } \\
\text { protegido". }\end{array}$ & $\begin{array}{l}\text { "Na verdade, música e estética } \\
\text { casam num registo "muito } \\
\text { trabalhado e rebuscado", tal como a } \\
\text { própria arquitetura" }\end{array}$ \\
\hline $\begin{array}{l}\text { “...o castelo era o enquadramento } \\
\text { perfeito para três dias de negro e de } \\
\text { música, para um público que } \\
\text { começou a ir a Leiria antes mesmo } \\
\text { dos concertos se organizarem em } \\
\text { festival” }\end{array}$ & $\begin{array}{l}\text { “...uma súbita indignação de alguns } \\
\text { setores da sociedade - a propósito } \\
\text { de um recente espetáculo de dança } \\
\text { considerada erótica - fez a câmara } \\
\text { recuar na cedência do espaço” }\end{array}$ & $\begin{array}{l}\text { "Acredito que os habitantes de Leiria } \\
\text { e os visitantes vão ficar } \\
\text { surpreendidos com a música, e } \\
\text { comprovar que afinal não é nem } \\
\text { inacessível nem } \\
\text { extraordinariamente agressiva, } \\
\text { como se faz crer" }\end{array}$ \\
\hline $\begin{array}{l}\text { “...quando a associação e a Câmara } \\
\text { de Leiria, em conjunto, decidiram } \\
\text { "resgatar o castelo de uma } \\
\text { penumbra onde estava já há muitos } \\
\text { anos" }\end{array}$ & $\begin{array}{l}\text { “...as tais forças ocultas continuam } \\
\text { a olhar para nós como se fôssemos } \\
\text { uns diabinhos, o que é } \\
\text { absolutamente inaceitável” }\end{array}$ & $\begin{array}{l}\text { “...estamos a falar de público que } \\
\text { vem de muitos sítios da Europa, que } \\
\text { trazem filhos, que são advogados, } \\
\text { médicos, engenheiros, operários, } \\
\text { não interessa. Que são católicos, na } \\
\text { sua maioria" }\end{array}$ \\
\hline $\begin{array}{l}\text { “...é a mesma cidade que está a } \\
\text { candidatar-se a Capital Europeia da } \\
\text { Cultura, e que se habituou a ver as } \\
\text { esplanadas da Praça Rodrigues } \\
\text { Lobo vestidas de negro" }\end{array}$ & $\begin{array}{l}\text { "...não foi o estilo de música que foi } \\
\text { censurado. Foi o tipo de público..." }\end{array}$ & $\begin{array}{l}\text { “...vão sempre "outros artistas que } \\
\text { não são góticos" }\end{array}$ \\
\hline
\end{tabular}




\section{Evolução do discurso}

Tomando como referrência as notícias publicadas nos anos 2010, 2013 e 2018, correspondentes às edições que foram consideradas, pelos elementos da Fade In, momentos-chave do evento ${ }^{1}$, identificaram-se notícias onde pudessem ser encontradas declarações tanto de organizadores ligados à Fade In como à CML. O intuito foi observar qual a evolução ocorrida no discurso proferido por ambos os parceiros em relação aos propósitos e objetivos do festival. Foi possível identificar duas linhas de abordagem: da parte da Fade In, responsável pela programação musical e cultural, o enfoque incide em dar a conhecer a cultura alternativa, desfazendo alguns estereótipos que lhe estão associados. Da parte dos organizadores da CML, o foco parece ter estado sempre mais do lado da possibilidade de utilizar o festival como forma de promoção da cidade (Tabela 2).

Tabela 2 Evolução do discurso dos organizadores (Fade In e CML) nos anos 2010, 2013 e 2018

\begin{tabular}{|c|c|c|c|c|c|}
\hline \multicolumn{2}{|c|}{2010} & \multicolumn{2}{|c|}{2013} & \multicolumn{2}{|c|}{2018} \\
\hline Fade In & CML & Fade In & CML & Fade In & $\mathrm{CML}$ \\
\hline $\begin{array}{l}\text { "O Entremuralhas } \\
\text { - Festival Gótico } \\
\text { realiza-se a } 27 \text { e } \\
28 \text { e pretende } \\
\text { "desmistificar" } \\
\text { algumas ideias } \\
\text { "erradas" sobre } \\
\text { o "movimento } \\
\text { gótico" (Região } \\
\text { de Leiria, 2010) }\end{array}$ & $\begin{array}{l}\text { "Este é um } \\
\text { festival único, } \\
\text { que vai projetar } \\
\text { o concelho de } \\
\text { Leiria e a } \\
\text { cultura pelo país } \\
\text { e } \\
\text { além-fronteiras" } \\
\text { (Região de Leiria, } \\
\text { 2010) }\end{array}$ & $\begin{array}{l}\text { "Não está } \\
\text { também de fora a } \\
\text { hipótese - e } \\
\text { dependendo dos } \\
\text { apoios que } \\
\text { venhamos a ter - } \\
\text { de haver um dia } \\
\text { zero com um } \\
\text { concerto gratuito } \\
\text { acessível a todos } \\
\text { os leirienses que } \\
\text { queiram, } \\
\text { definitivamente, } \\
\text { participar neste } \\
\text { evento que, } \\
\text { apesar de já ter } \\
\text { derrubado } \\
\text { muitas barreiras } \\
\text { psicológicas, } \\
\text { continua a ser } \\
\text { alvo de algumas } \\
\text { interpretações } \\
\text { que não } \\
\text { correspondem à } \\
\text { sua essência." } \\
\text { (Região de Leiria, } \\
\text { 2013) }\end{array}$ & $\begin{array}{l}\text { “...à quarta } \\
\text { edição o } \\
\text { Entremuralhas } \\
\text { cimentou-se, } \\
\text { definitivamente, } \\
\text { como um evento } \\
\text { que coloca } \\
\text { Leiria na rota } \\
\text { dos grandes } \\
\text { eventos } \\
\text { culturais } \\
\text { nacionais e } \\
\text { internacionais." } \\
\text { (Região de Leiria, } \\
\text { 2013) }\end{array}$ & $\begin{array}{l}\text { "Todos vão poder } \\
\text { ver artistas que } \\
\text { normalmente vão } \\
\text { ao Entremuralhas } \\
\text { e centenas de } \\
\text { pessoas que } \\
\text { nunca foram ao } \\
\text { festival, por } \\
\text { preconceito, } \\
\text { medo ou } \\
\text { impossibilidade } \\
\text { económica ou } \\
\text { até física, vão } \\
\text { ter uma } \\
\text { pequena } \\
\text { amostra do que } \\
\text { acontece } \\
\text { entremuralhas e } \\
\text { acontecerá agora } \\
\text { extramuralhas". } \\
\text { (SIC Notícias, } \\
\text { 2018) }\end{array}$ & $\begin{array}{l}\text { “Vamos ter muita } \\
\text { gente a visitar } \\
\text { Leiria, além dos } \\
\text { habituais } \\
\text { visitantes do } \\
\text { festival. } \\
\text { Podemos mudar } \\
\text { o paradigma, o } \\
\text { cenário, a } \\
\text { beleza, no que } \\
\text { diz respeito à } \\
\text { relação com a } \\
\text { cidade”. (SIC } \\
\text { Notícias, 2018) } \\
\end{array}$ \\
\hline
\end{tabular}




\section{Perceções da comunidade gótica}

Com o intuito de complementar as informações resultantes da análise de notícias e documentos com as perceções dos membros da subcultura em realção à importância do festival para a sua vivência diária enquanto góticos, foram inquiridos nove elementos desta comunidade.

Todos os respondentes, à execção de um, manifestam terem níveis de envolvimento com a cultura gótica consideráveis e em dois casos o festival Entremuralhas desempenhou um papel importante para essa relação. Cinco dos respondentes são de Leiria ou concelhos limítrofes e os restantes de outros pontos do país.

Os esterótipos com que mais vezes têm de lidar na sua vivência diária prendem-se com a roupa e o estilo, que motivam comentários devido à cor negra predominante, mas também aos folhos e aspeto vitoriano de algumas das roupas. É em relação à personalidade que mais vezes os inquiridos lidam com qualificações, sendo chamados de depressivos, deprimidos, estranhos, misteriosos e mórbidos. Referem também outros termos com que têm de lidar como satânicos, drogados, vampiros, mas também boneca ou princesa. Quando se coloca a questão em relação às tensões que ocorrem entre os góticos e a restante comunidade de Leiria, a esmagadora maioria afirma que não experencia essa tensão, antes sentimentos de estranheza ou de curiosidade. É interessante verificar que os dois únicos casos que informam focos de tensão (relacionados com a religião e com a estereotipização feita pelos mais jovens) são da zona de Leiria, o que parece indiciar que durante o festival este tipo de tensões não se faz sentir.

Todos revelam que o festival é importante para eles próprios e para a comunidade gótica, pelo seu caráter único, pelo ambiente e pela possibilidade de assisitir a concertos de bandas conhecidas ou novas que de outra forma não conseguiriam. Uma das inquiridas afirma que, para ela, o evento "é um ambiente em que me sinto aceite por quem sou, sem rótulos", reforçando a ideia de communitas que este tipo de eventos permite aos seus participantes. Esta ideia é afirmada também por outra das inquiridas:

...no caso da comunidade a grande importância passa por ser um festival gótico o que dá a oportunidade à comunidade de se juntar, partilhar momentos, conhecer pessoas com os mesmos gostos que provavelmente grande parte como eu não teriam a oportunidade se não fosse o festival.

Quando se procura saber se os inquiridos sentem mudanças na relação com a comunidade local decorrentes do festival, há uma forte tendência para reconhecer que se tem assistido a uma maior abertura e interesse pela cultura gótica e que o 
festival tem sido algo positivo para a cidade, mobilizando a restante comunidade local, que aguarda com expectativa a realização do evento seguinte. Na Tabela 3 são apresentas as transcrições das respostas dos participantes a esta questão.

Tabela 3 Respostas dos inquiridos em relação à evolução da relação da comunidade local com a comunidade gótica

\begin{tabular}{|c|c|c|c|}
\hline $\begin{array}{l}\text { "Sinto ano após ano } \\
\text { sempre mais abertura" } \\
\text { "Todos são aceites com } \\
\text { respeito" }\end{array}$ & $\begin{array}{l}\text { "Eu acho que sim, mas } \\
\text { não tenho a certeza pois } \\
\text { não pertencia à } \\
\text { comunidade antes de ir ao } \\
\text { festival." }\end{array}$ & $\begin{array}{l}\text { "Sempre responderam } \\
\text { bem. E continuam a } \\
\text { responder bem. E de ano } \\
\text { para ano noto que estão } \\
\text { tão ansiosos quanto os } \\
\text { que participam no festival." }\end{array}$ & $\begin{array}{l}\text { "Mudou ao longo dos anos, } \\
\text { pois o festival trouxe } \\
\text { riqueza à cidade e } \\
\text { diversidade." }\end{array}$ \\
\hline $\begin{array}{l}\text { "Mudou muito. A } \\
\text { estranheza e o preconceito } \\
\text { foram-se dissipando ao } \\
\text { longo dos anos graças ao } \\
\text { conví vio entre ambas as } \\
\text { comunidades." }\end{array}$ & $\begin{array}{l}\text { "Acho que tem melhorado, } \\
\text { é bom para a economia e } \\
\text { mentalidade local e é um } \\
\text { bom espaço para quem } \\
\text { quer visitar e ir ao evento." }\end{array}$ & $\begin{array}{l}\text { "Mudou e de uma maneira } \\
\text { engraçada e positiva; as } \\
\text { pessoas falam-me várias } \\
\text { vezes sobre o festival, ou } \\
\text { se vou ou questionam se } \\
\text { sou gótica, que gostam de } \\
\text { ver as pessoas a passar } \\
\text { vestidos a rigor." }\end{array}$ & $\begin{array}{l}\text { "Sim, se calhar, não sei } \\
\text { porque nunca conversei } \\
\text { com ninguém, mas } \\
\text { provavelmente olham com } \\
\text { outros olhos." }\end{array}$ \\
\hline
\end{tabular}

Todos afirmam que o impacto para Leiria tem sido muito positivo e que o festival se constitui já como uma marca cultural da cidade, que permite a Leiria distinguir-se culturalmente das outras capitais de distrito, dando um contributo importante para a evolução do turismo da cidade, uma vez que traz muitas pessoas de outros países, colocando a cidade no mapa de artistas internacionais e conferindo visibilidade mundial a Leiria, transformando o evento em marco e símbolo da cidade.

Impacto económico do festival

Embora se tenha procurado perceber o impacto económico do festival para Leiria, a inexistência de dados desagregados não permitiu realizar esse exercício. Ainda assim, no que respeita ao número de hópedes e dormidas em Leiria no mês de agosto observa-se um aumento desde 2010². Importa referir que na edição de 2015 surgiu a necessidade de encontrar um espaço alternativo ao alojamento tradicional (hotéis, pensões e AL) para conseguir albergar todos os festivaleiros. Como se pode observar numa notícia divulgada na altura ${ }^{3}$, o Estádio de Leiria foi preparado para acolher 40 festivaleiros, informação que demonstra o impacto do evento na capacidade de alojamento existente na cidade. A evolução das dormidas e hóspedes durante o mês do festival é apresentada nas Figuras 2 e 3. 


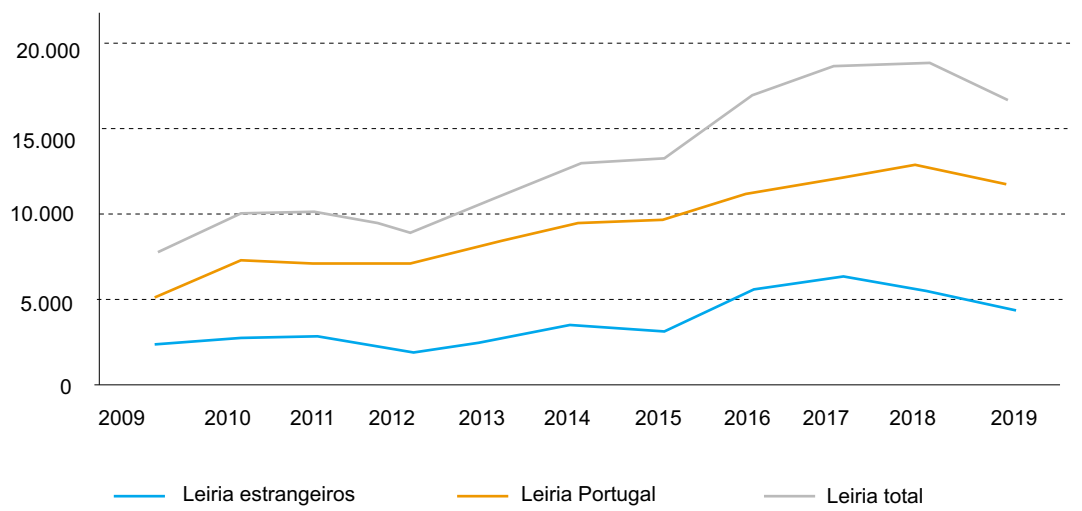

Figura 2 Evolução dormidas Leiria Agosto 2010-2019

Fonte: INE (dados definitivos), cedido por Turismo de Portugal.

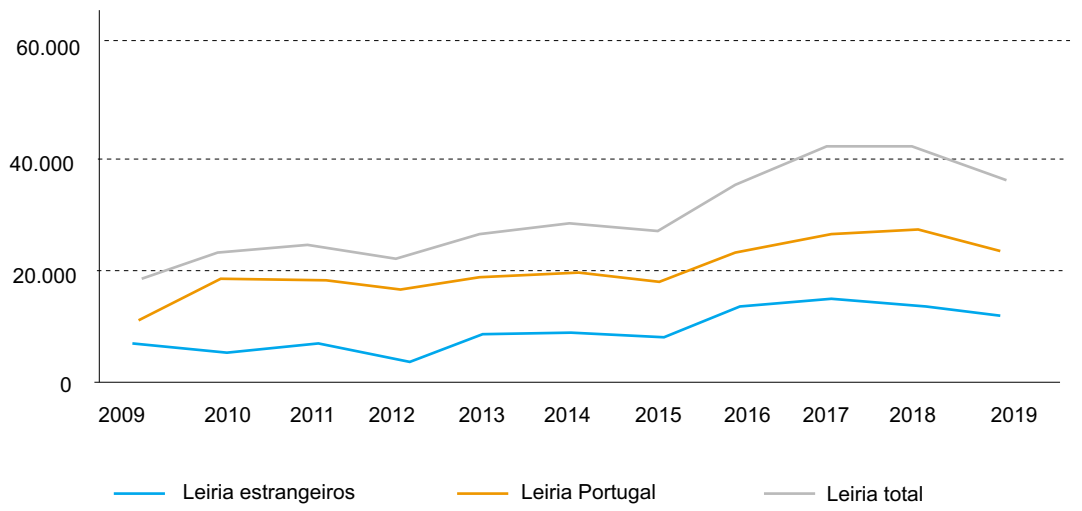

Figura 3 Evolução hóspedes Leiria Agosto 2010-2019

Fonte: INE (dados definitivos), cedido por Turismo de Portugal.

\section{Conclusões}

Os festivais assumem um protagonismo importante para gerar imaginários que capitalizam a economia simbólica das cidades, uma vez que são momentos privilegiados de contacto entre culturas diferentes que permitem construir imagens de maior consmopolitismo, diversidade e tolerância.

Os eventos culturais oferecem a possibilidade de colocar em contacto, ainda que por períodos relativamente curtos, culturas diferentes, permitindo que esse imergir momentâneo na cultura desconhecida permita desfazer alguns dos estereótipos 
previamento criados. A análise das notícias e outros documentos publicados durante as dez edições do festival gótico Entremuralhas permite identificar duas abordagens diferentes no tocante aos objetivos do evento no que concerne aos seus dois organizadores. Por um lado, os responsáveis da Fade In procuram dar a conhecer à comunidade local uma cultura alternativa marcada por estereótipos e preconceitos. A Câmara Municipal de Leiria norteia a sua associação ao festival pela vontade de participar num projeto que dê visibilidade à cidade e ajude a inscrevê-la no roteiro dos espaços de cultura ao nível nacional e internacional.

A análise documental permite perceber que o festival Entremuralhas colocou Leiria no rota dos festivais de música gótica, criando um espaço para a música alternativa e contribuindo para a promoção da cidade, constituindo-se atualmente como um dos principais marcos culturais da cidade. Os testemunhos da comunidade gótica revelam que se vai assistindo a uma maior abertura e interesse por parte da comunidade local em relação a esta cultura e a este evento.

Conclui-se que a o festival Entremuralhas tem contribuído para uma aproximação entre cultura dominante e alternativa em Leiria. Não obstante esta aproximação, episódios como o da mudança de local dois espetáculos na edição do Entremuralhas 2018 indiciam que persistem ainda tensões e subsistem alguns preconceitos por parte de algumas pessoas em relação a esta subcultura, havendo ainda um caminho a trilhar até que a comunidade gótica de Leiria consiga fazer a sua transição da margem para o centro.

\section{Agradecimentos}

A Miguel Silva, por proporcionar o acesso aos respondentes do inquérito; e ao Turismo de Portugal, por fornecer os dados relativos às dormidas e hóspedes de Leiria.

\section{Notas}

Por decisão pessoal, o autor do texto escreve segundo o novo acordo ortográfico.

1 Informação resultante de uma entrevista exploratória feita no âmbito da preparação do trabalho de campo para a Tese de Doutoramento, atualmente em curso, do autor deste artigo intitulada Culturas entre Muralhas. (Sub)Culturas e Estilos de Vida alternativos nas pequenas Cidades: o Festival Entremuralhas e os Góticos em Leiria.

2 Estes dados devem ser lidos com o necessário distanciamento, pois tratam-se de dados respeitantes a todo o mês de agosto e não apenas aos dias do evento. 
3 O vídeo completo desta notícia pode ser visto em

https:// www.youtube.com/watch?v=5hzp9bh-pow consultado em 24 de novembro 2020 .

\section{Referências}

Abreu, P. (2001). Públicos culturais nas cidades ou das cidades? Algumas observações a partir de um estudo comparado em cidades portuguesas. In M. A. Pinheiro, L. V. Baptista \& M. J. Vaz (Eds.), Cidade e metrópole. Centralidades e marginalidades ( $1^{\mathrm{a}} \mathrm{ed}$.) (pp. 159-170). Oeiras: Celta Editora.

Abreu, P., \& Ferreira, C. (2016). Apresentação: A cidade, as artes e a cultura. Revista Crítica de Ciências Sociais, (67), 3-6.

Antunes, C. (2020, 3 de fevereiro). Boom Festival gera 55 milhões de euros no interior. Expresso 2466, Caderno Economia, p. 14.

Baker, A. (2019). The great music city exploring music, space and identity. Cham: Pallgrave Macmillan.

Becker, H. (1973). Outsiders: Studies in the sociology of deviance. Nova Iorque: The Free Press.

Becker, H. (1997). The Culture of a deviant group: The “jazz” musician. In K. Gelder \& S. Thornton (Eds.), The subcultures reader (pp. 55-65). Londres e Nova Iorque: Routledge.

Bennett, A. (2004). Consolidating the music scenes perspective. Poetics, 32, 223-234. doi:10.1016/j.poetic.2004.05.004

Bennett, A., Taylor, J., \& Woodward, I. (2014). The festivalization of culture. Surrey e Burlington: Ashgate Publishing Limited.

Bennett, A., \& Woodward, I. (2014). Festival spaces, identity, experience and belonging. In The festivalization of culture (pp. 11-25). Surrey e Burlington: Ashgate Publishing Limited.

Berzano, L., \& Genova, C. (2015). Lifestyle and subcultures - History and a new perspective. Nova Iorque e Oxon: Taylor and Francis.

Brake, M. (1995). Comparative youth culture: The sociology of youth culture and youth subcultures in America, Britain and Canada. Londres e Nova Iorque: Routledge.

Brás, N., Mendes, J., Guerreiro, M., \& Sequeira, B. D. (2019). How do residents experience their own festivals? In J. Mair (Ed.), The Routledge handbook of festivals (pp. 263-272). Abingdon e Nova Iorque: Rouledge.

Brill, D. (2008). Goth culture: Gender, sexuality and style. Oxford: BERG.

Chalcraft, J., Delanty, G., \& Sassatelli, M. (2014). Varieties of cosmopolitanism in art festivals. In A. Bennett, J. Taylor \& I. Woodward (Eds.), The festivalization of culture (pp. 109-129). Surrey e Burlington: Ashgate Publishing Limited.

Daskalaki, M., \& Mould, O. L. I. (2013). Beyond urban subcultures: Urban subversions as rhizomatic social formations. International Journal of Urban and Regional Research, 37, 1-18. doi:10.1111/j.1468-2427.2012.01198.x

SOCIOLOGIA ON LINE, n. ${ }^{\circ}$ 25, abril 2021, pp. $62-85$ | DOI: 10.30553/sociologiaonline.2021.25.3 
Diário de Leiria. (2014). Entremuralhas aumentou a notoriedade de Leiria a nível nacional e internacional. Diário de Leiria, p. 2.

Diário de Notícias. (2018a, 10 de agosto). Depois da polémica da dança, a música gótica fica fora de igreja de Leiria. Diário de Notícias. Disponível em https://www.dn.pt/cultura/interior/depois-da-polemica-da-danca-a-musica-goti ca-fica-fora-de-igreja-de-leiria-9706135.html

Diário de Notícias. (2018b, 25 de agosto). Extramuralhas: Leiria vestida a rigor para o maior festival gótico da Europa. Diário de Notícias. Disponível em https:// www.dn.pt/edicao-do-dia/25-ago-2018/extramuralhas-leiria-vestida-arigor-para-o-maior-festival-gotico-da-europa-9759349.html

Evans, G. (2011). Cities of culture and the regeneration game. London Journal of Tourism, Sport and Creative Industries, 5(6), 5-18.

Expresso. (2017). Dossiê especial Expresso. Expresso, (2326).

Fauquet-Alekhine, P. (2015). Clothing-based discrimination at work: The case of the goth subculture. British Journal of Education, Society \& Behavioural Science, 13(4), 1-16. doi:10.9734/bjesbs/2016/21592

Ferreira, C. (2010). Cultura e regeneração urbana: Novas e velhas agendas da política cultural para as cidades. Revista TOMO, 0(16), 29. doi:10.21669/tomo.v0i16.518

Fischer, C. S. (1975). Toward a subcultural theory of urbanism. American Journal of Sociology, 80(6), 1319-1341. doi:10.1086/225993

Fortuna, C. (2016). Recensão: Lisboa Multicultural [M. Margarida Marques (org.), 2014, Lisboa, Fim de Século]. Sociologia, Problemas e Práticas, 82, 167-170. doi:10.7458/spp2016827404

Garland, J., \& Hodkinson, P. (2014). “F**king freak! What the hell do you think you look like?": Experiences of targeted victimization among goths and developing notions of hate crime. British Journal of Criminology, 54(4), 613-631. doi:10.1093/bjc/azu018

Gelder, K. (2007). Subcultures. Cultural histories and social practice. Londres e Nova Iorque: Routledge.

Gelder, K., \& Thornton, S. (1997). The subcultures reader. Londres e Nova Iorque: Routledge.

Goodland, C. M. E., \& Bibby, M. (2007). Undead goth subculture. Londres: Duke University Press.

Goulding, C., \& Saren, M. (2016). Transformation, transcendence, and temporality in theatrical consumption. Journal of Business Research, 69(1), 216-223. doi:10.1016/j.jbusres.2015.07.034

Guerra, P. (2010). A instável leveza do Rock. Génese, dinâmica e consolidação do rock alternativo em Portugal (1980-2010). Universidade do Porto, Porto.

Guerra, P., \& Moura, L. A. (2016). Uma outra Sonic youth: A génese do barulho nas Caldas da Rainha. In IS Working Papers (Vol. 3).

Haenfler, R. (2014). Subcultures the basics. Londres e Nova Iorque: Routledge.

Hall, S. (2001). Cultural studies. In S. Seideman \& J. C. Alexander (Eds.), The new social theory reader (pp. 88-100). Londres e Nova Iorque: Routledge. 
Hall, S., \& Jefferson, T. (2003). Resistance through rituals youth subcultures in post-war Britain. Londres: Taylor \& Francis.

Healey, K., \& Fraser, L. (2017). A common darkness: Style and spirituality in Goth subculture. Journal of Popular Music Studies, 29(3), 1-14. doi:10.1111/jpms.12231

Hebdige, D. (2005). Subculture the meaning of style. Londres e Nova Iorque: Routledge.

Hodkinson, P. (2002). Goth. Identity, style and subculture. Oxford e Nova Iorque: BERG.

Hoffert, J., \& Nym, A. (Eds.). (2011). Black celebration: 20 Jahre Wave-Gotik-Treffen (1. Aufl). Leipzig: Plöttner.

Humberstone, K. (2011). Monumentum II. In J. Hoffert \& A. Nym (Eds.), Black celebration (pp. 136-144). Leipzig: Plöttner.

Innerarity, D. (2006). O novo espaço público. Alfragide: Teorema.

Issit, M. L. (2011). GOTH: A Guide to an American subculture. Santa Barbara, Denver e Oxford: Greenwood.

Jornal de Leiria. (2016, 25 de agosto). Quem diria que o negro pode ser tão colorido? Jornal de Leiria. Disponível em https://www.jornaldeleiria.pt/noticia/quem-diria-que-o-negro-pode-ser-tao-colorido-4858

Lefebvre, H. (2012). O direito à cidade. Lisboa: Letra Livre.

Lopes, J. T. (2000). A cidade e a cultura, um estudo sobre as práticas culturais urbanas. Porto: Edições Afrontamento.

Martin, S. (2002). Gothic scholars don't wear black: Gothic studies and gothic subcultures. Gothic Studies, 4(1), 28-43. doi:10.7227/gs.4.1.3

Matzke, P., Seeliger, T., \& Stieg, E. (Eds.). (2000). Gothic (2. ${ }^{\text {a }}$ ed.). Berlim: Schwarzkopf \& Schwarzkopf.

Muggleton, D. (2000). Inside subculture the postmodern meaning of style. Oxford e Nova Iorque: Berg.

Muggleton, D., \& Weinzierl, R. (2003). The Post-subcultures reader. Oxford e Nova Iorque: Berg.

Newman, S. (2018). The evolution of the perceptions of the goth subculture. Johnsons e Wales University.

Redhead, S. (1997). Subcultures to clubcultures. An introduction to popular cultural studies. Oxford e Massachusets: Blackwell Publishers Inc.

Região de Leiria. (2010, 9 de agosto). Castelo de Leiria recebe festival internacional de música gótica. Região de Leiria. Disponível em

https://www.regiaodeleiria.pt/2010/08/castelo-de-leiria-recebe-festival-internacionalde-musica-gotica/

Região de Leiria. (2013, 28 de agosto). Entremuralhas 2014 pode ter concerto grátis para derrubar "barreiras psicológicas". Região de Leiria. Disponível em https://www.regiaodeleiria.pt/2013/08/entremuralhas2014/

Richards, G. (2015). Events in the network society: The role of pulsar and iterative events. Event Management, 19(4), 553-566. doi:10.3727/152599515X14465748512849

Richards, G., \& Palmer, R. (2010). Eventful cities. Cultural management and urban revitalisation. Oxford e Burlington: Elsevier. 
Sandercock, L. (2003). Cosmopolis II Mongrel Cities in the 21st Century. Londres e Nova Iorque: Continuum.

Sapo.pt. (2018, 13 de agosto). Festival Entremuralhas marcado por saída de concertos de igreja de Leiria. SAPO 24. Disponível em

https:/ /24.sapo.pt/vida/artigos/festival-entremuralhas-marcado-por-saida-de-co ncertos-de-igreja-de-leiria

SIC Notícias. (2018, 9 de fevereiro). Festival gótico de Leiria sai do castelo e muda nome. SIC Notícias. Disponível em

// sicnoticias.pt/cultura/2018-02-09-Festival-gotico-de-Leiria-sai-do-castelo-e-mu da-nome

Siegel, C. (2005). Goth's dark empire. Bloomington e Indianapolis: Indiana Press.

Spracklen, K., \& Spracklen, B. (2014). The strange and spooky battle over bats and black dresses: The commodification of Whitby Goth Weekend and the loss of a subculture. Tourist Studies, 14(1), 86-102. doi:10.1177/1468797613511688

Spracklen, K., \& Spracklen, B. (2018). The evolution of Goth culture: The origins and deeds of the new Goths (1 $1^{\text {st }}$ ed.). Reino Unido/ América do Norte: Emerald Publishing.

Thornton, S. (1995). Club cultures music, media and subcultural capital. Cambridge: Polity Press.

TSF. (2018, 24 de agosto). Góticos, punks e xamãs. O festival que primeiro estranha-se, depois entranha-se. TSF. Disponível em https://www.tsf.pt/sociedade/interior/goticos-punks-e-xamas-o-festival-que-pri meiro-estranha-se-depois-entranha-se-9758533.html

Ultraje.pt. (2016, 27 de julho). As razões para irmos ao Entremuralhas - 25/26/27 Agosto. Leiria. Ultraje. Metal \&amp; Rock Online. Disponível em https://ultraje.pt/entremuralhas2016-preview/

Ulusoy, E. (2016). Subcultural escapades via music consumption: Identity transformations and extraordinary experiences in Dionysian music subcultures. Journal of Business Research, 69(1), 244-254. doi:10.1016/j.jbusres.2015.07.037

Valentim, M. F., Manuel, V., Marques, L., Madureira, Á. J., \& Marques, D. R. (2017). Município de Leiria Ata n.o 18/17 (Vol. 1079).

Williams, J. P. (2014). Subcultures and Deviance. In M. Dellwing, J. Kotarba \& N, Pino. (Eds.), The death and ressurection of deviance (pp. 108-121). Hampshire e Nova Iorque: Pallgrave Macmillan UK.

Williams, J. P. (2019). Subculture's not dead! Checking the pulse of subculture studies through a review of 'subcultures, popular music and political change' and 'youth cultures and subcultures: Australian perspectives'. YOUNG, 27(1), 89-105. doi: $10.1177 / 1103308818761271$

Wirth, L. (2001). O urbanismo como modo de vida. In C. Fortuna (Ed.), Cidade, cultura e globalização ( $2^{\mathrm{a}}$ ed.) (pp. 45-65). Oeiras: Celta Editora.

Wynn, J. R., \& Yetis-Bayraktar, A. (2016). The sites and sounds of placemaking: Branding, festivalization, and the contemporary city. Journal of Popular Music Studies, 28(2), 204-223. doi:10.1111/jpms.12169 
Zukin, S. (1995). The cultures of cities. Massachusetts e Nova Iorque: Blackwell Publishing.

Zukin, S. (2014, setembro). Dialogue on urban cultures: Globalization and culture in an urbanizing world. Comunicação apresentada no World Urban Forum, $2^{\mathrm{a}}$ Edição, Barcelona. Disponível em http://citeseerx.ist.psu.edu/viewdoc/summary?doi=10.1.1.200.8998

Data de submissão: 11/06/2020 | Data de aceitação: 04/02/2021

(c) (1) 